School of Finance

University of St.Gallen

THE VALUE OF INTEREST RATE GUARANTEES IN

PARTICIPATING LIFE INSURANCE CONTRACTS: STATUS

Quo and Alternative Product Design

MARTIN ELING

STEFAN HOLDER

WORKING PAPERS ON FINANCE NO. 2012/21

INSTITUT FÜR VERSICHERUNGSWIRTSCHAFT (I.VW - HSG)

SEPTEMBER 2012 


\title{
The value of interest rate guarantees in participating life insurance contracts: Status quo and alternative product design
}

\author{
Martin Eling ${ }^{\mathrm{a}, 1}$, Stefan Holder ${ }^{\mathrm{b}, *}$ \\ ${ }^{a}$ Institute of Insurance Economics, University of St. Gallen, Kirchlistrasse 2, 9010 St. \\ Gallen, Switzerland \\ ${ }^{b}$ DFG Research Training Group 1100, University of Ulm, Helmholtzstrasse 22, 89081 Ulm, \\ Germany
}

\begin{abstract}
We compare cliquet-style interest rate guarantees used in German participating life insurance contracts across different economic environments. These guarantees are proportional to the average market interest rate at contract inception and typically determined as 60 percent of the 10-year rolling average of government bond yields. Currently, however, in the face of prolonged low interest rates and stricter solvency regulation, the continued existence of this product type is being seriously questioned. A discussion of alternative guarantee designs is thus highly relevant. To this end, we perform a comparative analysis of contracts sold in different interest rate environments with regard to the guarantee value and show that the current practice of proportional guarantees leads to higher guarantee values the lower the market interest rate is. We also observe an increased interest rate sensitivity. Additionally, alternative product designs that mitigate the interest rate dependency of the guarantee value are illustrated and assessed from the policyholder perspective.
\end{abstract}

Keywords: participating life insurance contract, 60 percent rule, interest rate guarantee, alternative guarantee design, comparative analysis

JEL: G13, G22

\footnotetext{
${ }^{*}$ Corresponding author. Tel.: +49 731 5031081; fax: +49 7315023548 .

Email addresses: martin.eling@unisg.ch (Martin Eling), stefan.holder@uni-ulm.de (Stefan Holder)

${ }^{1}$ Tel.: +41 71 2247980; fax: +41712247990.
}

Preprint submitted to Insurance: Mathematics and Economics

September 30, 2012 


\section{Introduction}

Interest rate guarantees are a common feature of traditional life insurance products. We focus on the situation in the German market with so-called cliquetstyle guarantees, under which the insurance company promises to credit the policyholders' account with at least a guaranteed rate of return every year. As the policyholders' account also contains previous years' surplus, the guarantee is implicitly applied to the distributed surplus as well. The guaranteed interest rate is proportional to the current average market interest rate at contract inception, typically 60 percent of the 10-year rolling average of government bond yields. Hence, we refer to it as the 60 percent rule. ${ }^{2}$

Over the last decade, the life insurance industry's situation has deteriorated due to substantial changes in both the economic and regulatory environment. Under the upcoming Solvency II regime, the industry's solvency requirements will be fundamentally reformed and lead to higher capital requirements for these traditional interest rate guarantees. At the same time, insurers' earnings have been adversely affected by the sustained decline of returns on low-risk fixedincome assets. In Germany, life insurers are under additional pressure due to peculiarities of national regulation, such as the participation of policyholders in asset valuation reserves upon contract termination (see $§ 153$ German Insurance Contract Act, VVG) as this accelerates the replacement of old high yield bonds with new lower yielding bonds (Fromme, 2011). Stocks and other asset classes cannot be used to compensate for low earnings from fixed income due to the significantly increased volatility of capital markets. The former strategy of buying low-risk bonds is thus no longer possible to the extent traditional interest rate guarantees would require. Unfavorable development of the capital market and shortcomings in risk management have lead to the default of life insurers

\footnotetext{
${ }^{2}$ The 60 percent rule is a result of the establishment of a common European insurance market in 1994 and the accompanying unification of national regulatory systems. See, e.g., Eling and Holder (2012).
} 
in several countries. ${ }^{3}$ Therefore, participating life insurance contracts and their embedded options, such as interest rate guarantees, have received a great deal of attention and analysis from academia over the last decade. ${ }^{4}$

There are two prevailing approaches to analyze financial guarantees in life insurance: the actuarial and the financial. Consequently, most of the literature on the topic can be divided into two groups. Moreover, work such as Barbarin and Devolder (2005), Gatzert and Kling (2007), and Graf et al. (2011) combine both approaches.

The actuarial approach focuses on analyzing the risk of different contract specifications and surplus distribution schemes under an objective probability measure. Participating contracts are analyzed by Bartels and Veselčić (2009), Cummins et al. (2007), Kling et al. (2007a,b), and Rymaszewski (2011). Cummins et al. (2007) provide an empirical comparison of life insurance contracts typical of several European markets and those common in the United States by computing risk-return profiles. Different surplus distribution schemes and their interaction with the guaranteed rate with respect to the insurer's shortfall risk are analyzed by Kling et al. (2007a,b). Bartels and Veselčić (2009) extend this model by a jump process asset framework and dynamic asset allocation strategies in order to quantify the model risk. Rymaszewski (2011) also considers the risk arising from interest rate guarantees and quantifies the diversification effect caused by pooling undistributed surplus among inhomogeneous policyholder groups.

The financial approach is primarily concerned with fair pricing of contracts and the options embedded therein. Many scholars analyze participating contracts including Bacinello (2001, 2003), Bauer et al. (2006), Büsing (2005), Grosen and Jørgensen (2000, 2002), Hansen and Miltersen (2002), Zaglauer and

\footnotetext{
${ }^{3}$ Information about defaults in the United States (First Executive Corporation and others), Japan (Nissan Mutual and others), Germany (Mannheimer Lebensversicherung), and the United Kingdom (Equitable Life) can be found, e.g., in Briys and de Varenne (1997), Suzuki (2004), Himstedt (2004), and O'Brien (2006), respectively.

${ }^{4}$ Equity-linked life insurance has been subject to extensive academic research as well. However, this contract type is outside the scope of this article. The reader is referred to Bacinello and Persson (2002) for a categorization of the literature on equity-linked life insurance.
} 
Bauer (2008), and Zemp (2011). Bacinello (2001, 2003) show how to decompose a fair participating Italian contract into three parts (basic contract, participation, and surrender option), which can be priced separately. For the case of Denmark, Grosen and Jørgensen (2000) find the fair contract value to depend significantly on the bonus policy applied and the spread between market rate and guaranteed rate. Hansen and Miltersen (2002) demonstrate that collecting an annual fee as compensation for providing interest rate guarantees allows for a greater contract variety compared to receiving a share of the distributed surplus. Bauer et al. (2006) analyze cliquet-style guarantees typical of German contracts and find fair contract values to be sensitive to several model parameters, including the risk-free rate. Zaglauer and Bauer (2008) provide an extension with respect to stochastic interest rates and show that the value of the embedded options changes significantly, whereas the total contract value is only moderately affected. Zemp (2011) compares the British, Danish, German and Italian bonus distribution system with regard to risk valuation and shows that the Italian one is most sensitive to changes in asset volatility.

The extant literature tends to focus on pricing existing contracts in different economic environments. Thus the guaranteed rate is typically considered as fixed and independent of the economic environment. We take a step forward and analyze the 60 percent rule under different economic environments (high/low interest rates). A second contribution of this paper is to analyze alternative designs for the guaranteed rate in traditional products. To our knowledge, this has not yet been done in the academic literature, although it is a topic of high interest and attention among practitioners. To date, the solutions most frequently suggested are temporary and reduced guarantees (see, e.g., Goecke, 2011; Heinen, 2011; Pohl, 2011).

This article presents a comparative analysis of the 60 percent rule and alternative product designs in different interest rate environments with respect to the fair guarantee value. The analysis is designed as a ceteris paribus analysis and we consider a typical German participating life insurance contract where the guaranteed rate depends on the long-term average of interest rates. We adopt 
the valuation framework presented in Bauer et al. (2006) and its extension for stochastic interest rates by Zaglauer and Bauer (2008). Their methodology allows us to decompose the contract into its components and hence price the interest rate guarantee separately. To compare contracts sold in different economic environments, we calibrate the surplus-related parameters so that the compared contracts have a net present value of zero under the risk-neutral pricing measure. We also assess the policyholder utility of the proposed alternative designs.

We find that the current practice of setting the guaranteed rate leads to significantly higher guarantee values in times of low interest rates and to an increased sensitivity to interest rates. However, alternative products can be designed to mitigate the interest rate dependency of the guarantee value. Our findings also show that from the policyholder perspective there seems to be no substantial difference between the different guarantee types. These results contribute to the ongoing discussion of how to reform insurance regulation and product design to cope with the pressures arising from low interest rates. Risk managers and regulators will particularly benefit from this analysis as we identify the shortcomings of proportional cliquet-style interest rate guarantee schemes. In our analysis we consider a typical German contract, but the model is sufficiently flexible so that our analysis can easily be extended to accommodate other regulatory regimes with cliquet-style guarantees.

The remainder of this paper is structured as follows. In Sections 2 and 3 we briefly introduce the general modeling framework and valuation methodology used by Bauer et al. (2006) and Zaglauer and Bauer (2008). A description of the different product designs is presented in Section 4. We also discuss adjustments to the existing model that are necessary to incorporate the new guarantee types and the utility analysis. Numerical results for both, the 60 percent rule and its alternatives are given in Section 5. In Section 6 we conclude and identify areas for further research. 


\section{The Model}

In the following, most of our notation is adapted from Zaglauer and Bauer (2008). We assume that the insurance company's financial situation at time $t$ is represented by the simplified balance sheet shown in Table 1 . Here, $A_{t}$ denotes the market value of the insurer's assets, $L_{t}$ the book value of the policyholders' account, and the residual $R_{t}=L_{t}-A_{t}$ denotes the reserve account at time $t$. In this context, we refer to $R_{t}$ as asset valuation reserves, even though it might also consist of other components, e.g., equity.

Table 1: Simplified balance sheet

\begin{tabular}{c|c} 
Assets & Liabilities \\
\hline$A_{t}$ & $L_{t}$ \\
& $R_{t}$ \\
\hline$A_{t}$ & $A_{t}$
\end{tabular}

For the sake of simplicity, we consider a very basic contract type, a singlepremium term-fix insurance maturing after $T$ years, and ignore any charges. Given this contract, the benefit $L_{T}$ is always paid at time $T$, regardless of whether the insured person is alive or dead. Thus the payoff does not depend on biometric circumstances but is completely determined by the bonus policy and performance of the insurer's assets. This allows us to analyze the pure financial risk arising from the interest rate guarantee.

A typical feature of traditional German life insurance contracts is the cliquetstyle interest rate guarantee. Insurance companies are obliged to credit the policyholders' account with a minimum interest rate $g$ each year. On top of the guaranteed rate, the company also credits some portion of the annual surplus in order to allow the policyholders to participate in the investment results. So that its shareholders also can participate in the investment results, the insurance company pays them dividends $d_{t}$ which are calculated as a portion $\alpha$ of the surplus credited to the policyholders. Since the amount paid as dividends leaves the company, the notation has to be adjusted accordingly. Therefore, we define $A_{t}^{-}$and $A_{t}^{+}=A_{t}^{-}-d_{t}$ to denote the value of the asset portfolio shortly before and after the dividend payment. The surplus participation is subject to 
certain legal constraints. According to German legislation, at least $\delta=90 \%$ of the earnings on book values must be distributed to the policyholders (see $\$ 4$ Minimum Funding Ordinance, MindZV). The insurer's earnings on book values are subject to various accounting rules and therefore usually differ from the earnings on market values $A_{t}^{-}-A_{t-1}^{+}$. To approximate the book value earnings, we follow the approach proposed by Kling et al. (2007b) and assume that a constant portion $y$ of the earnings on market values has to be displayed as earnings on book values in the balance sheet.

In addition to legal constraints, strategic management decisions play an important role in the actual surplus distribution. In recent years, the prevailing practice of German life insurers was to grant a rather constant rate of interest based on the level of their reserves. To achieve this goal, asset reserves were accumulated in years with high investment returns and released in years with poor returns in order to keep the granted rate stable. Only if the reserves reached a critically low (high) level, would the companies adjust their surplus policy and decrease (increase) the amount credited accordingly. ${ }^{5}$ The insurance company thus credits a constant target rate of interest $z>g$ to the policyholders' account as long as the reserve quota $x_{t}=\frac{R_{t}}{L_{t}}=\frac{A_{t}^{-}-d_{t}-L_{t}}{L_{t}}$ remains within a prespecified range $[a, b]$. Kling et al. (2007b) show that this is equivalent to the conditions

$$
\begin{aligned}
& A_{t}^{-} \geq((1+a)(1+z)+\alpha(z-g)) L_{t-1} \\
& A_{t}^{-} \leq((1+b)(1+z)+\alpha(z-g)) L_{t-1} .
\end{aligned}
$$

If crediting $z$ leads to a reserve quota above $b$, the company credits exactly the rate that leads to $x_{t}=b$. In the event crediting the target rate $z$ leads to $x_{t}<a$, the rate credited is adjusted to achieve $x_{t}=a$. However, the interest rate credited to the policyholders' account is never below the legal requirements, that is, the larger of guaranteed interest and minimum participation rate. Summarizing the above description and taking the legally required minimum surplus

\footnotetext{
${ }^{5} \mathrm{~A}$ detailed description of the corresponding formulas can be found in Kling et al. (2007b), who differentiate two cases: the MUST- and the IS-case. The MUST-case is based on the legal requirements, whereas the IS-case describes the insurers' actual behavior. In the analysis presented here, we are interested in the actual behavior and thus ignore the MUST-case.
} 
participation into account, we obtain

$$
\begin{aligned}
L_{t}= & (1+g) L_{t-1} \\
& +\max \left\{\left[\delta y\left(A_{t}^{-}-A_{t-1}^{+}\right)-g L_{t-1}\right]^{+},(z-g) L_{t-1}\right. \\
& \times \mathbf{1}_{\left\{((1+a)(1+z)+\alpha(z-g)) L_{t-1} \leq A_{t}^{-} \leq((1+b)(1+z)+\alpha(z-g)) L_{t-1}\right\}} \\
& +\frac{1}{1+a+\alpha}\left[A_{t}^{-}-(1+g)(1+a) L_{t-1}\right] \\
& \times \mathbf{1}_{\left\{(1+a)(1+g) L_{t-1} \leq A_{t}^{-} \leq((1+a)(1+z)+\alpha(z-g)) L_{t-1}\right\}} \\
& +\frac{1}{1+b+\alpha}\left[A_{t}^{-}-(1+g)(1+b) L_{t-1}\right] \\
& \left.\times \mathbf{1}_{\left\{((1+b)(1+z)+\alpha(z-g)) L_{t-1}<A_{t}^{-}\right\}}\right\}
\end{aligned}
$$

for the liabilities, and analogously

$$
\begin{aligned}
d_{t}= & \max \left\{\alpha\left[\delta y\left(A_{t}^{-}-A_{t-1}^{+}\right)-g L_{t-1}\right]^{+},\right. \\
& \alpha(z-g) L_{t-1} \\
& \times \mathbf{1}_{\left\{((1+a)(1+z)+\alpha(z-g)) L_{t-1} \leq A_{t}^{-} \leq((1+b)(1+z)+\alpha(z-g)) L_{t-1}\right\}} \\
& +\frac{\alpha}{1+\alpha+a}\left[A_{t}^{-}-(1+g)(1+a) L_{t-1}\right] \\
& \times \mathbf{1}_{\left\{(1+a)(1+g) L_{t-1} \leq A_{t}^{-} \leq((1+a)(1+z)+\alpha(z-g)) L_{t-1}\right\}} \\
& +\frac{\alpha}{1+b+\alpha}\left[A_{t}^{-}-(1+g)(1+b) L_{t-1}\right] \\
& \left.\times \mathbf{1}_{\left\{((1+b)(1+z)+\alpha(z-g)) L_{t-1}<A_{t}^{-}\right\}}\right\}
\end{aligned}
$$

for the dividend payments.

The boundaries $a$ and $b$ for the reserve quota can be set to reflect the actual situation. Here, the lower bound corresponds to solvency requirements (e.g., minimum capital requirement) mandating the company to keep a minimum level of reserves. The upper bound can be considered the result of management decisions to remain competitive in the market.

\section{Risk-Neutral Valuation}

For the purpose of risk-neutral valuation, we fix a finite time horizon $T$ and assume, as is usual, the existence of a probability space $(\Omega, \mathcal{F}, \mathbb{Q})$ equipped with 
a filtration $\mathbb{F}=\left(\mathcal{F}_{t}\right)_{t \in[0, T]}$. As the benefit $L_{T}$ is always paid at maturity and no surrender option is included, the risk-neutral contract value $P^{*}$ with respect to the numéraire process $\left(B_{t}\right)_{t \in[0, T]}=\left(\exp \left(\int_{0}^{t} r_{s} \mathrm{~d} s\right)\right)_{t \in[0, T]}$ is given as

$$
P^{*}=\mathbb{E}_{\mathbb{Q}}\left[L_{T} B_{T}^{-1}\right]
$$

We assume the insurer invests all money in a reference portfolio, which serves as an approximation of the insurer's real asset portfolio. This reference portfolio consists of assets actually traded on the market and its composition is never modified. In addition to the initial premium payment, the company has the following cash flows.

1. If the return on the reference portfolio is insufficient to meet the interest rate guarantee, even after completely releasing the reserve, the company receives a capital shot $c_{t}$. The risk-neutral value at contract inception of these payments is given by

$$
C_{0}=\mathbb{E}_{\mathbb{Q}}\left[\sum_{t=1}^{T} c_{t} B_{t}^{-1}\right]
$$

and can be considered as the value of the interest rate guarantee.

2. At each time $t=1, \ldots, T$ the shareholdes are paid a dividend. The $t=0$ risk-neutral value of these payments is given by

$$
D_{0}=\mathbb{E}_{\mathbb{Q}}\left[\sum_{t=1}^{T} d_{t} B_{t}^{-1}\right] .
$$

The risk-neutral value of the change of reserves is given by

$$
\Delta R_{0}=\mathbb{E}_{\mathbb{Q}}\left[R_{T} B_{T}^{-1}\right]-R_{0}
$$

and describes how the reserve situation is affected by selling this type of contract.

Based on the above cash flows, Bauer et al. (2006) obtain a decomposition of the contract value, which can be represented either directly, as expectation of 
the discounted benefit $L_{T}$, or as the sum of the embedded options:

$$
P^{*}=\mathbb{E}_{\mathbb{Q}}\left[L_{T} B_{T}^{-1}\right]=P+C_{0}-D_{0}-\Delta R_{0}
$$

For a fair contract, the initial premium $P$ must equal the contract value $P^{*}$, thus the value of the interest rate guarantee should equal the values of dividend payments and change of reserve account, i.e.,

$$
C_{0} \stackrel{!}{=} D_{0}+\Delta R_{0}
$$

To model the above framework, we assume a frictionless and arbitrage-free financial market in which investors can trade continuously. We further assume the reference portfolio is well-diversified and evolves according to the stochastic differential equation

$$
\frac{\mathrm{d} A_{t}}{A_{t}}=r_{t} \mathrm{~d} t+\sigma_{A} \rho \mathrm{d} W_{t}+\sigma_{A} \sqrt{1-\rho^{2}} \mathrm{~d} Z_{t}, \quad A_{0}>0
$$

where $W_{t}$ and $Z_{t}$ are independent $\mathbb{Q}$-Brownian motions, $\sigma_{A}>0$ denotes the portfolio's volatility, and $\rho \in[0,1]$ is the correlation between $A$ and the risk-free rate $r_{t}$. Further, we assume $r_{t}$ to follow the Cox et al. (1985, hereafter, CIR) model, i.e.,

$$
\mathrm{d} r_{t}=\kappa\left(\theta-r_{t}\right) \mathrm{d} t+\sigma_{r} \sqrt{r_{t}} \mathrm{~d} W_{t}, \quad r_{0}>0
$$

for positive parameters $\kappa, \theta$ and $\sigma_{r}{ }^{6}$ To ensure $r_{t}>0 \forall t$, we impose the condition $2 \kappa \theta>\sigma_{r}^{2}$ (cp. Brigo and Mercurio, 2006). Applying the Itô-Doeblin formula to Equation (10), we obtain

$$
\begin{aligned}
A_{t}^{-}= & A_{t-1}^{+} \exp \left(\int_{t-1}^{t} r_{s} \mathrm{~d} s-\frac{\sigma_{A}^{2}}{2}\right. \\
& \left.+\int_{t-1}^{t} \rho \sigma_{A} \mathrm{~d} W_{s}+\int_{t-1}^{t} \sqrt{1-\rho^{2}} \sigma_{A} \mathrm{~d} Z_{s}\right) .
\end{aligned}
$$

\footnotetext{
${ }^{6}$ Zaglauer and Bauer (2008) additionally consider an Ornstein-Uhlenbeck process for the short rate. However, in this case, $r_{t}>0$ is not guaranteed and we obtain a substantial number of negative sample paths. Thus we restrict ourselves to the CIR model, even though this requires a discretization approach in the implementation.
} 
Taking dividend payments to shareholders and capital shots (which ensure $R_{t} \geq 0$ at all times) into account, we have $A_{t}^{+}=\max \left\{A_{t}^{-}-d_{t}, L_{t}\right\}$ which completes the description of the reference portfolio evolution.

As the capital shots depend on specific development of the liabilities over time, the value of the interest rate guarantee is path dependent and we are not aware of any analytical formula for $C_{0}$ in this setting. Thus we rely on Monte Carlo methods to price the contract components. $L_{t}$ can be simulated straightforwardly based on Equation (2). To simulate the evolution of $A_{t}$, we follow Zaglauer and Bauer (2008) and define $r_{t}^{A}$ as the rate of return of the reference portfolio for the interval $[t-1, t)$ to obtain

$$
\begin{aligned}
r_{t}^{A}= & \frac{A_{t}^{-}-A_{t-1}^{+}}{A_{t-1}^{+}} \\
= & \exp \left\{\int_{t-1}^{t} r_{s} \mathrm{~d} s-\frac{\sigma_{A}^{2}}{2}+\rho \sigma_{A} \int_{t-1}^{t} \mathrm{~d} W_{s}\right. \\
& \left.+\sqrt{1-\rho^{2}} \sigma_{A} \int_{t-1}^{t} \mathrm{~d} Z_{s}\right\}-1
\end{aligned}
$$

as a direct result of Equation (12). Since $r_{t}$ is assumed to follow the CIR model, it features a square-root diffusion term and the distribution of $\int_{t-1}^{t} r_{s} \mathrm{~d} s$ cannot be determined explicitly. Therefore, we apply discretization methods that lead to

$$
\begin{aligned}
r_{t+\Delta} & =e^{-\kappa \Delta}\left(r_{t}-\theta\right)+\theta+\sigma_{r} \int_{t}^{t+\Delta} e^{-\kappa(t+\Delta-s)} \sqrt{r_{s}} \mathrm{~d} W_{s} \\
& \approx e^{-\kappa \Delta}\left(r_{t}-\theta\right)+\theta+\sigma_{r} e^{-\kappa \Delta} \sqrt{r_{t}}\left(W_{t+\Delta}-W_{t}\right)
\end{aligned}
$$

where the integral is approximated by its left-hand Riemann sum and $\Delta$ is sufficiently small. Even though we choose the parameters for the CIR model such that $r_{t}>0 \mathbb{Q}$-almost surely, the discretization error can still lead to negative values for the short rate. To overcome this problem, we replace negative short rates with zero. 


\section{Analysis Design}

\subsection{Alternative Guarantee Designs}

In our framework, the guaranteed rate is assumed to be non-negative and to depend solely on time and economic environment. Further, we assume the guaranteed rate to be valid for at least one year. Thus it can be expressed as a non-negative, discrete-time process $g_{t}$ that is adapted to $\mathbb{F}$. For $t=0, \ldots, T-1$, $g_{t}$ denotes the guaranteed rate for the time $[t, t+1)$. We define $\mathbb{T}=\left\{\tau_{j}: j=\right.$ $0, \ldots, k\}$ to be the set of renewal times $0=\tau_{0}<\cdots<\tau_{k}<T$ at which the guaranteed interest rate is changed. We assume this to happen at most once a year, thus $k<T$.

The assumption $g_{t} \geq 0$ implies that even in years with negative portfolio returns, the insurance company has to at least guarantee the preservation of the policyholders' account. This asymmetric participation in asset returns is typical of traditional life insurance and in many countries even encouraged by the government since cash-accumulating life insurance is considered an important supplement to the statutory pension. In the comparative analysis, we examine the following designs for the guaranteed rate (assuming a contract maturity of $T=10$ years and a long-term average of the 10 -year spot rate $\vartheta$ ):

1. 60 percent rule: This guarantee type is the status quo in the German market, meaning that 60 percent of the average market rate is passed on as the guaranteed rate. This is equivalent to $\mathbb{T}=\left\{\tau_{0}\right\}$ and $g_{t} \equiv 0.6 \vartheta$ in the above framework.

2. Reduced guarantee: This guarantee type is a generalization of the 60 percent rule. Instead of 60 percent, a portion $\pi<0.6$ of the average market rate is given as the guarantee which is equivalent to $\mathbb{T}=\left\{\tau_{0}\right\}$ and $g_{t} \equiv \pi \vartheta$. In the analysis we consider the cases $\pi=0.4$ (40 percent rule) and $\pi=0.2$ (20 percent rule).

3. Money-back guarantee: This guarantee type is the special case $\pi=0$ of the 
reduced guarantee. It ensures preservation of the policyholders' account. ${ }^{7}$ In the above framework, this corresponds to $\mathbb{T}=\left\{\tau_{0}\right\}$ and $g_{t} \equiv 0$.

4. Temporary guarantee: The guaranteed rate for the first $\tau_{1}$ contract years is set at inception. For the remaining time until maturity, the insurance company only guarantees the year-by-year preservation of the policyhold-

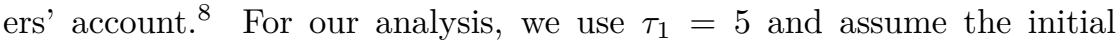
guaranteed rate to be set in accordance with the 60 percent rule which corresponds to $\mathbb{T}=\left\{\tau_{0}, \tau_{1}\right\}$ and $g_{t}=0.6 \vartheta \cdot \mathbf{1}_{\left\{\tau_{0} \leq t<\tau_{1}\right\}}$.

5. Guarantee with fixed safety margin: The guaranteed rate is determined such that the spread between average market rate at inception and guaranteed rate is constant across different interest rate environments. In the above framework, this is equivalent to $\mathbb{T}=\left\{\tau_{0}\right\}$ and $g_{t} \equiv \max \{\vartheta-c ; 0\}$ where $c$ denotes the safety margin.

To accommodate the above alternative guarantee designs, we modify the Bauer et al. (2006) model by replacing the constant guaranteed rate $g$ with the vector $\left(g_{t}\right)_{t=0}^{T-1}$ whose entries are determined according to the chosen guarantee type. Equations (2) and (3) for liabilities and dividend payments can be easily adapted by substituting $g$ with $g_{t-1}, t=1, \ldots, T$, where $g_{t-1}$ denotes the guaranteed rate for the $t$-th contract year.

Each economic environment is represented by a different long-term average of the 10-year spot rate. We choose this value due to its central importance in determining the maximum statutory valuation rate and thus the guaranteed rate in Germany (cp. Eling and Holder, 2012). Given a long-term average $\vartheta$ of the 10-year spot rate, we obtain a consistent short rate mean reversion level $\theta$ for Equation (11) by using the affine linear properties of the CIR model. These ensure the linear relationship $R_{t, \tau}=\alpha_{\tau}+\beta_{\tau} r_{t}$ between the time $t$ spot rate with maturity $\tau$ and the short rate. For any fixed maturity $\tau$, the coefficients

\footnotetext{
${ }^{7}$ As we consider a contract without costs, the savings premium and the gross premium coincide, meaning that account preservation (applies to the savings premium) and moneyback guarantee (applies to the gross premiums) are equivalent. However, in the real world where costs are incurred, one must differentiate between these two guarantee types.

${ }^{8} \mathrm{~A}$ less conservative approach would be to renew the guaranteed rate after $\tau_{1}$ years based on the prevailing market rate at that time.
} 
$\alpha_{\tau}$ and $\beta_{\tau}$ do not depend on $t$, but only on the model parameters $\kappa, \sigma_{r}$ and $\theta$ (see Brigo and Mercurio (2006) for details). Thus, we obtain

$$
\begin{aligned}
\vartheta & =\lim _{t \rightarrow \infty} \mathbb{E}_{\mathbb{Q}}\left[R_{t, \tau} \mid \mathcal{F}_{0}\right] \\
& =\alpha_{\tau}+\beta_{\tau} \lim _{t \rightarrow \infty} \mathbb{E}_{\mathbb{Q}}\left[r_{t} \mid \mathcal{F}_{0}\right] \\
& =\alpha_{\tau}+\beta_{\tau} \theta
\end{aligned}
$$

Solving this equation for $\theta$ yields

$$
\theta=\frac{\vartheta}{\beta_{\tau}-2 \kappa \tilde{\alpha}_{\tau} /\left(\tau \sigma_{r}^{2}\right)}=: f(\vartheta)
$$

where

$$
\begin{aligned}
& \tilde{\alpha}_{\tau}=\ln \left(\frac{2 h e^{\tau(\kappa+h) / 2}}{2 h+(\kappa+h)\left(e^{\tau h}-1\right)}\right), \\
& \beta_{\tau}=\frac{1}{\tau} \cdot \frac{2\left(e^{\tau h}-1\right)}{2 h+(\kappa+h)\left(e^{\tau h}-1\right)},
\end{aligned}
$$

and $h=\sqrt{\kappa^{2}+2 \sigma_{r}^{2}}$.

The initial short rate value $r_{0}$ and the target rate $z$ have to be adjusted to the economic environment too. As the considered environments are fictitious, we let $r_{0}$ coincide with $\theta$. Furthermore, we assume the target rate $z$ credited to the policyholders' account to be proportional to the average level of interest rates, i.e., $z=z_{f} \vartheta$. This approach also simplifies the calibration procedure described below.

\subsection{Model Calibration}

To compare guarantee values across different economic environments, we use an approach similar to the one in Zemp (2011). We numerically calibrate the surplus-related contract parameters (reserve corridor $[a, b]$ and target rate $z$ ) such that for each environment $\vartheta$ the compared contracts have a net present 
value of zero, that is, satisfy Equation (9). ${ }^{9}$ This is achieved by minimizing the expression $\left(C_{0}-D_{0}-\Delta R_{0}\right)^{2}$. As mentioned above, we model $z=z_{f} \vartheta$ and thus calibrate $z_{f}$, which allows us to use the same constraints for each $\vartheta$. If we applied the calibration procedure directly to $z$, we would need a rather wide range of admissible values to accommodate all environments simultaneously, leading to less stable results. The calibration is based on 10,000 sample paths for the guarantee value using Matlab's fmincon procedure with the interior-point algorithm. ${ }^{10}$ Given the nature of the calibration problem, the solution is usually not unique. Thus, to obtain reasonable parameter combinations, we impose the constraints

$$
\begin{array}{ll}
0 \leq a \leq 0.1, & a \leq b-0.1, \\
0 \leq b \leq 0.35, & 0.5 \leq z_{f} \leq 1.75,
\end{array}
$$

during the optimization where the condition $a \leq b-0.1$ ensures the existence of an actual reserve corridor and prevents solutions of the form $a=b$. The remaining constraints for $a$ and $b$ were chosen based on Kling et al. (2007b). However, we allow a somewhat wider range as the average market rates considered in the analysis are notably higher or lower than the ones in Kling et al. (2007b). The range of admissible values for $z_{f}$ was approximated from the literature. To check our results for robustness, we repeat the calibration procedure for multiple initial values. In the subsequent analysis, results are presented for the initial vector

\footnotetext{
${ }^{9}$ We choose this approach to ensure comparability between contracts sold in different economic environments. Alternatively, the condition of fair contracts could be dropped and the guarantee value determined at relevant points in the past (i.e. whenever the regulator lowered the guarantee rate). This would allow for an analysis of the actual value of interest rate guarantees sold in the past.

${ }^{10} \mathrm{An}$ alternative approach would be to use non-gradient-based optimization techniques such as simulated annealing or differential evolution, which are designed for situations in which the objective function is stochastic or noisy. For an introduction to simulated annealing, see, e.g., van Laarhoven and Aarts (1987). The differential evolution technique was introduced by Storn and Price (1997). For more details on differential evolution and a comprehensive overview of different algorithms, see Price et al. (2005) and Mullen et al. (2011), respectively.
} 
$\left(a_{0}, b_{0}, z_{f 0}\right)=(0.05,0.3,0.75)$. The full set of results is available upon request. ${ }^{11}$

To isolate the effects caused by changes in the interest rate environment, we design the analysis as a ceteris paribus analysis, that is, we fix all parameters that are independent of $\vartheta$. We choose the parametrization suggested in Zaglauer and Bauer (2008, Table 5, column "1996-2006") and adjust it to our modeling framework. Table 2 summarizes the basic parameter configuration for the analysis.

Table 2: Basic parameter configuration for the numerical analysis

\begin{tabular}{|c|c|c|c|c|c|}
\hline \multicolumn{2}{|c|}{ Capital market } & \multicolumn{2}{|c|}{ Contract } & \multicolumn{2}{|c|}{ Company } \\
\hline$\kappa$ & 0.19 & $P$ & 10,000 & {$[a, b]$} & $\mathrm{a}$ \\
\hline$\sigma_{r}$ & 0.0304 & $T$ & 10 & $x_{0}$ & $\{0,0.05,0.1\}$ \\
\hline$\theta$ & $f(\vartheta)$ & $g$ & $0.6 \vartheta$ & $\alpha$ & 0.05 \\
\hline$r_{0}$ & $\theta$ & & & $\delta$ & 0.9 \\
\hline$\sigma_{A}$ & 0.036 & & & $y$ & 0.5 \\
\hline$\rho$ & 0.03 & & & $z$ & $\mathrm{a}$ \\
\hline$\lambda_{A}$ & $0.03^{\mathrm{b}}$ & & & & \\
\hline$\lambda_{r}$ & $0.01^{\mathrm{b}}$ & & & & \\
\hline
\end{tabular}

${ }^{\mathrm{a}}$ Determined by the numerical calibration procedure.

$\mathrm{b}$ The parameters $\lambda_{A}$ and $\lambda_{r}$ are formally introduced in Section 4.3. $\lambda_{A}$ is chosen as suggested in Cappiello et al. (2008).

\subsection{Policyholder Utility Analysis}

To assess the alternative guarantee designs from the policyholder perspective, we apply a utility analysis similar to that of Broeders et al. (2011) to the terminal contract payoff $L_{T}$. The representative policyholder is assumed to be risk-averse and to have a power utility function $U$ given by

$$
U(x)=\frac{x^{1-\gamma}}{1-\gamma}, \quad \gamma \neq 1, \quad \gamma>0,
$$

where $\gamma$ is the coefficient of relative risk aversion. To simplify matters, we do not compare the expected policyholder utility directly but determine for each

\footnotetext{
${ }^{11}$ Different initial values lead to slightly different fair guarantees values. However, the overall characteristics remain the same and thus the results are comparable. Additionally, we verify the stability of the guarantee value estimation by computing the relative standard deviation of the estimator based on 100 runs for a fixed level of initial reserves and a fixed set of optimal parameters. We find that, except for the money-back guarantee, the guarantee value estimation is more precise when average market rates are low. However, we cannot identify a clear trend as to for which guarantee type the estimation works best.
} 
guarantee design and economic environment the certainty equivalent $C E$, which is defined by

$$
U(C E)=\mathbb{E}_{\mathbb{P}}\left[U\left(L_{T}\right)\right]
$$

The certainty equivalent is the amount of contract payoff that has a utility equal to the expected utility of the payoff distribution $L_{T}$. Given the above utility function, a higher certainty equivalent implies a higher utility and thus a more preferable guarantee design from the policyholder perspective.

When conducting the analysis, we first determine the surplus parameters leading to a fair contract (see Section 4.2) and then compute the certainty equivalent within the particular setting. The latter step requires reference portfolio evolution under the objective probability measure $\mathbb{P}$. To this end, we introduce the equity risk premium, $\lambda_{A}$, and the market price of interest rate risk, $\lambda_{r}$. Using Girsanov's theorem (see, e.g., Shreve, 2004) we find that the reference portfolio evolves under $\mathbb{P}$ according to

$$
\frac{\mathrm{d} A_{t}}{A_{t}}=\left(r_{t}+\lambda_{A}\right) \mathrm{d} t+\sigma_{A} \rho \mathrm{d} \widetilde{W}_{t}+\sigma_{A} \sqrt{1-\rho^{2}} \mathrm{~d} \widetilde{Z}_{t},
$$

where $\widetilde{W}_{t}$ and $\widetilde{Z}_{t}$ are independent $\mathbb{P}$-Brownian motions. The short rate dynamics change to

$$
\mathrm{d} r_{t}=\tilde{\kappa}\left(\tilde{\theta}-r_{t}\right) \mathrm{d} t+\sigma_{r} \sqrt{r_{t}} \mathrm{~d} \widetilde{W}_{t}
$$

where $\tilde{\kappa}=\kappa-\lambda_{r} \sigma_{r}$ and $\tilde{\theta}=\frac{\kappa}{\kappa-\lambda_{r} \sigma_{r}} \theta$.

\section{Numerical Results}

In this section, we analyze the fair guarantee value in different interest rate environments, examine how assumptions about the regulatory parameters $y$ and $\delta$ impact the different guarantee types, and quantify the model risk with respect to asset volatility. In a last step, we compare the policyholder utility of the alternative designs. It might happen that the calibration procedure stops prematurely at a local minimum which then does not imply a fair contract. In some of these cases, we can manually find optimal parameter combinations. However, 
since this approach is rather arbitrary, we do not include those results in the subsequent analysis.

\subsection{Guarantee Value}

Figure 1 shows the fair guarantee value for contracts sold in different economic environments under the current 60 percent rule and the alternative designs introduced in Section 4.1. The optimal surplus parameters and the corresponding decomposition of the fair contract value are shown in Tables A1 to A6 in the Appendix.

Figure 1a illustrates how different economic environments $\vartheta$ and initial reserve levels $x_{0}$ affect the fair guarantee value $C_{0}$ under the 60 percent rule. In low interest rate environments, we find that the guarantee increases significantly in value and is highly sensitive to further changes in the average market rate. According to the fair contract condition (9), any increase in the guarantee value has to be compensated by an equal change of $D_{0}+\Delta R_{0}$. In contrast to the value of dividend payments, $D_{0}$, which decreases in low interest environments, the expected change in reserves, $\Delta R_{0}$, strongly increases. This implies that the shareholders receive less compensation for their investment in the company and more money is kept as reserve for future generations of policyholders.

For higher market rates, we observe a notably lower and less sensitive guarantee value. Under both variations of the reduced guarantee, as well as under the money-back and temporary guarantee, the guarantee value is generally lower but shows characteristics similar to the 60 percent rule. The increase for low interest rate levels, however, is more pronounced (see Figures 1b to 1e). For the reduced guarantee we observe the guarantee value to decrease with the portion $\pi$ of the average market rate passed on as guarantee. Thus, for $\pi \rightarrow 0$, this guarantee type converges to the money-back guarantee. Similar results are found for the temporary guarantee: for $\tau_{1} \rightarrow 0$ it converges to the money-back guarantee, for $\tau_{1} \rightarrow T$ to the 60 percent rule.

For the fixed safety margin guarantee (illustrated in Figure 1f), we observe some fluctuations of the otherwise rather stable guarantee value for $x_{0}=0$ and $x_{0}=0.1$. However, when comparing with results obtained by using differ- 


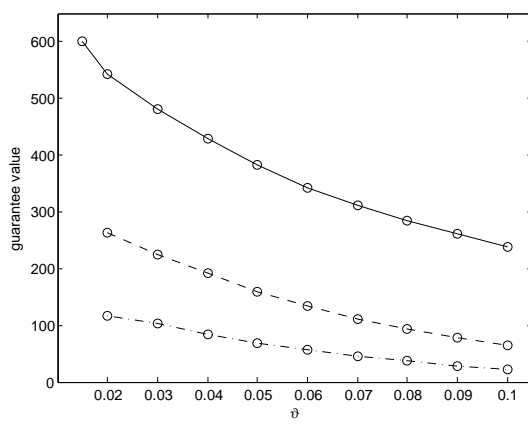

(a) Status quo (60 percent rule).

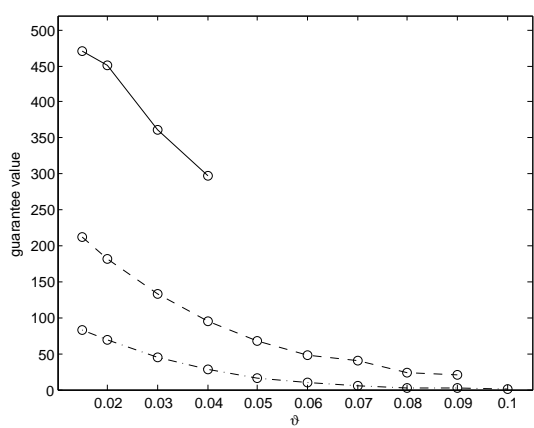

(c) Reduced guarantee (20 percent rule).

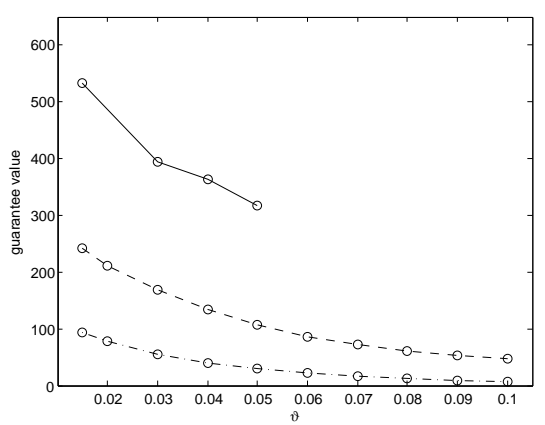

(e) Temporary guarantee (5 years).

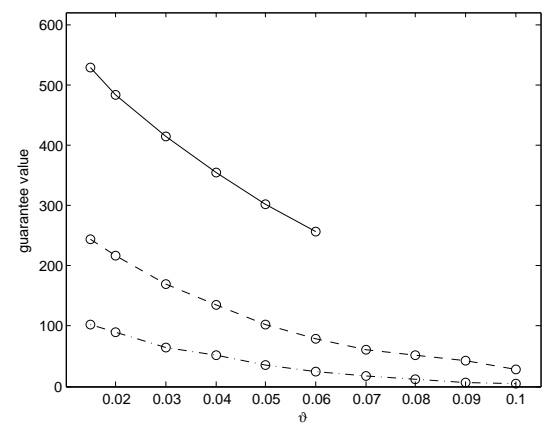

(b) Reduced guarantee (40 percent rule).

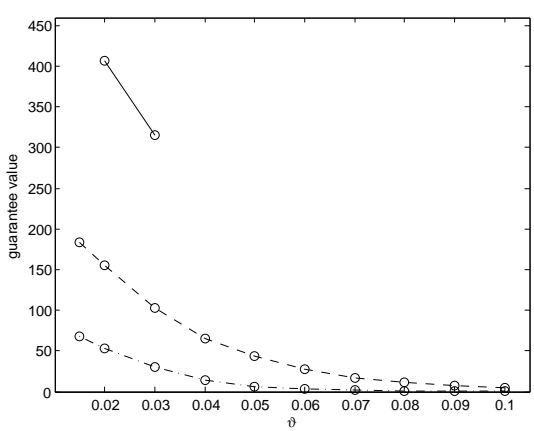

(d) Money-back guarantee.

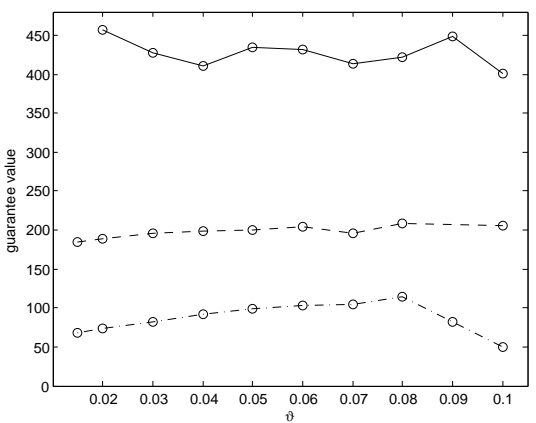

(f) Fixed safety margin guarantee (150 bps).

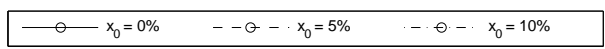

Figure 1: Guarantee value for the 60 percent rule and several alternative designs for different levels of initial reserves. 
ent initial values for the calibration, we find these fluctuations to be random. Thus, the fixed safety margin guarantee produces guarantee values independent of economic environment. Higher safety margins lead in general to lower guarantee values. However, due to the restriction $g \geq 0$ this guarantee type equals the money-back guarantee in low interest rate environments (in fact, these two guarantee types coincide for all average market rates below the chosen safety margin). This observation identifies the spread between average market rate and guaranteed rate to be one of the main determinants of the guarantee value.

In the case of no initial reserves, the guarantee accounts for up to 6 percent of the contract value. For a higher initial reserve level $x_{0}$, the guarantee value is lower for all designs and all average market rates as adverse portfolio returns can be compensated by releasing reserves. The values shown in Tables A1 to A6 suggest that the surplus parameters leading to fair contracts are relatively smooth in $\vartheta$. For all designs except the fixed safety margin guarantee we observe the lower bound $a$ of the reserve corridor to be decreasing in $\vartheta$ - meaning the company is crediting the target rate more often and thus is retaining less surplus to build reserves. The upper bound $b$ is in most cases only slightly decreasing in $\vartheta$ whereas the factor $z_{f}$ for the target rate increases notably. All these effects are less pronounced for increasing initial reserves. For the fixed safety margin guarantee, there is no clear trend in how the surplus parameters depend on the average market rate; they are rather stable, with only minor fluctuations. This smooth behavior can be used in cases where the numerical calibration method fails. For example, in the case of the fixed safety margin guarantee (Table A6), we show that even though the calibration procedure fails for $\left(\vartheta, x_{0}\right)=(0.09,0.05)$, the parameters $\left(a, b, z_{f}\right)=(0.0390,0.2693,1.2035)$ lead to a fair contract with the decomposition $C_{0}=207.12, D_{0}=87.86$ and $\Delta R_{0}=119.26$.

\subsection{Impact of the Regulatory Parameters $y$ and $\delta$}

Analyzing the impact of the parameters $y$ and $\delta$ on the fair guarantee value is particularly interesting as these parameters are subject to regulatory decisions. The regulator might modify accounting rules or minimum surplus requirements, leading to changes of $y$ and $\delta$. A different value for $y$ means that insurers will 
have to display a lower or higher portion of their market value earnings as book value earnings. As the minimum surplus is based on book value earnings, $y$ directly influences the amount of surplus distributed and thus the guarantee value. Changing $\delta$ also directly affects the minimum surplus.

For the case of $y$ we consider two scenarios: in one the approximation factor is changed to $y=0.3$, in the other to $y=0.7$. The higher the value for $y$, the more restrictions in asset valuation apply and book value earnings are closer to market value earnings. As the movement toward IFRS leads to more marketvalue-based accounting, the results for $y>0.5$ are of special importance. For $\delta$ we consider the assumption that the regulator suspends the minimum surplus requirements, that is, sets $\delta=0$.

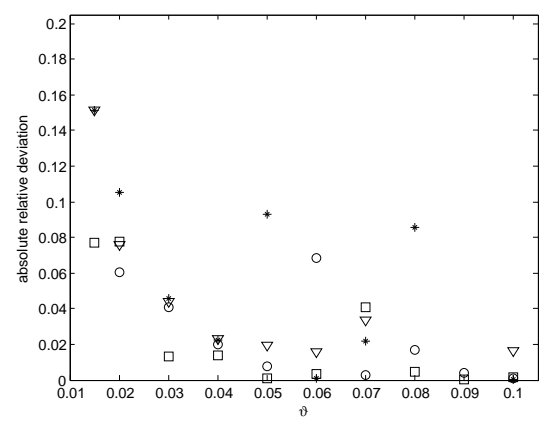

(a) $y=0.3$.

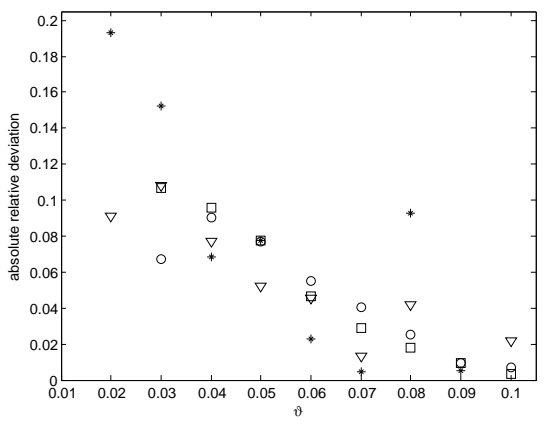

(b) $y=0.7$.

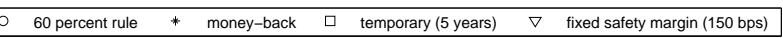

Figure 2: Absolute value of the deviation of the fair guarantee value relative to the base case of $y=0.5$ under different guarantee designs for $y \in\{0.3,0.7\}$.

Our results are inconclusive as to the impact of $y$ on the guarantee value. That is, we cannot identify a clear trend as to whether changing $y$ increases or decreases the fair guarantee value in general. Since the calibration procedure usually does not yield a unique solution, the impact of $y$ might vary depending on the chosen solution. Thus we show in Figure 2 the absolute value of the guarantee value's deviation relative to the base case $y=0.5$. When $y$ increases (more restrictions on determining book values), the guarantee value deviates more strongly from the base case compared to when $y$ decreases. In general, we 
observe that the higher the average market rate, the lower the deviation of the guarantee value. It is difficult to definitely state which guarantee design is most sensitive to changes in asset valuation restrictions. For $y=0.3$ it seems to be the money-back and fixed safety margin guarantee whereas for $y=0.7$ the numbers are ambiguous. An analysis of the influence of $\delta$ yields results comparable to the case of $y=0.3$ which can be explained by the functional form of the minimum surplus requirement.

\subsection{Model Risk}

For a fixed initial reserve quota of $x_{0}=0.05$, we assume the asset volatility $\sigma_{A}$ is lower/higher than initially anticipated. Figure 3 shows the relative deviation of the guarantee value when the asset volatility is overestimated by 50 bps (dashdot line), or underestimated by 50 bps (solid line), meaning that $\sigma_{A}$ is not 0.036 , but in fact 0.031 (overestimation) or 0.041 (underestimation). Again, cases where no fair contract was found are omitted (i.e., no marker for these is shown in Figure 3).

Figure 3 clarifies that underestimating the asset volatility generally results in a larger relative deviation compared to overestimation. Except for the fixed safety margin guarantee, the deviation increases with the average level of interest

rates. This effect is most pronounced for the money-back guarantee, where the relative deviation more than triples. The fixed safety margin guarantee, in contrast, shows a rather stable, slightly decreasing deviation. Of all the compared guarantee designs, the money-back guarantee is the most sensitive to a misspecification of asset volatility, thus exhibiting the highest model risk. For the chosen safety margin of $150 \mathrm{bps}$, the fixed safety margin guarantee has the lowest model risk.

\subsection{Policyholder Utility}

To conclude the analysis, we compare the different guarantee designs for fair contracts by assessing their utility from the policyholder perspective. To this end, we fix the initial reserve quota again at $x_{0}=0.05$ and assume policyholders with different degrees of risk aversion, represented by $\gamma=2,5$, and $10 \mathrm{in}$ 


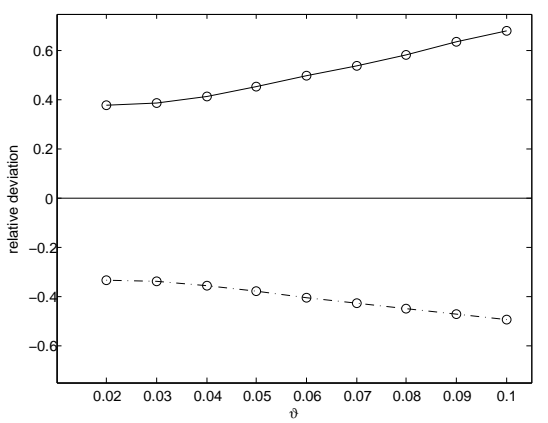

(a) Status quo (60 percent rule).

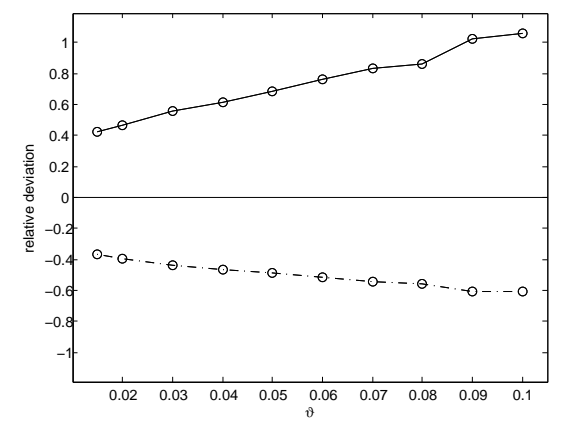

(c) Temporary guarantee (5 years).

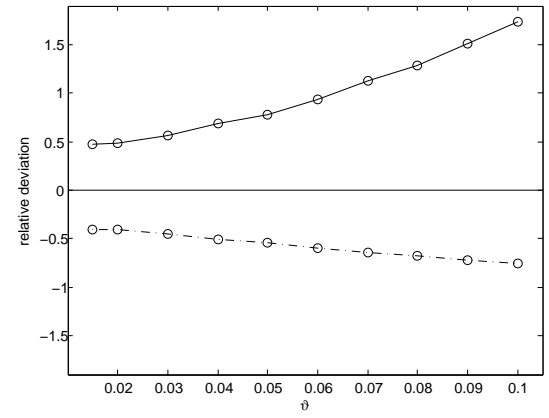

(b) Money-back guarantee.

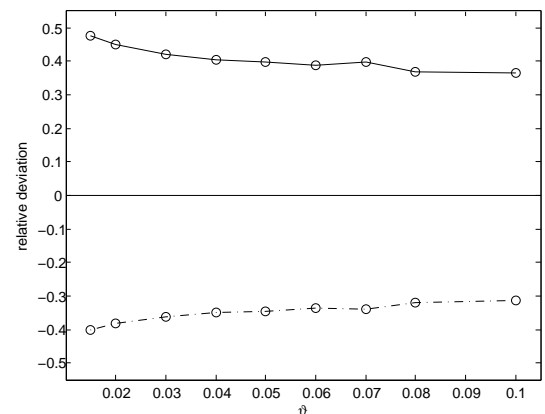

(d) Fixed safety margin guarantee (150 bps).

$-0-\cdots \sigma_{\mathrm{A}}-50 \mathrm{bps} \multimap-\sigma_{\mathrm{A}}+50 \mathrm{bps}$

Figure 3: Relative deviation of the guarantee value if the underlying asset volatility $\sigma_{A}$ is misspecified by \pm 50 bps.

Equation (17). The value $\gamma=2$ implies a very low degree of risk aversion (cp. Broeders et al., 2011), whereas $\gamma=5$ and 10 correspond to higher degrees of risk aversion.

To simplify matters, we compare the corresponding certainty equivalents, which are illustrated in Table 3. For each pair of $(\gamma, \vartheta)$, the highest value is printed in bold. We find that the certainty equivalent, and thus the expected policyholder utility, increases with the average market rate since this, ceteris paribus, increases the payoff. We also see that the expected utility decreases with increasing risk aversion, which can be explained by the functional form of the utility function. Compared to the certainty equivalent variation between the market rates and the risk aversion levels, the variation observed between 
the different guarantee types seems rather small. That is, we observe only relatively small deviations when comparing the certainty equivalent for a given combination of market rate and risk aversion level (the maximum reduction is 1.38 percent with the money-back guarantee, 10 percent average market interest rate, and the highest risk aversion). It thus seems that for the policyholder the differences in the expected utility between different guarantee types are not very substantial. A possible explanation for these rather small deviations is that the payoff is mainly determined by the reference portfolio's performance and not so much by the actual guarantee type.

For very low average market rates, the money-back and fixed safety margin guarantee yield the highest utility, independent of the degree of risk aversion. ${ }^{12}$ An explanation for this result might be that from the policyholder perspective a lower guarantee can lead to a higher expected utility as it imposes less restrictions on the insurer's asset allocation (cp. Wagner and Schmeiser, 2012). Our results allow no clear conclusion for the case of higher average market rates, but the fixed safety margin guarantee does appear to prevail for higher degrees of risk aversion.

An additional sensitivity analysis reveals that for all guarantee types the certainty equivalent is positively correlated with the equity risk premium $\lambda_{A}$ as it drives the reference portfolio's return. The correlation with $\lambda_{r}$ is also positive, albeit to a much lower extend. For different sets of optimal surplus parameters, we obtain comparable results.

\section{Summary}

This paper presents a comprehensive analysis of the impact of different economic environments on alternative interest rate guarantee designs, including the 60 percent rule typical of traditional life insurance products in Germany. The aim is to provide a better understanding of how value and sensitivity of

\footnotetext{
${ }^{12}$ Note that for an average market rate of 1.5 percent the money-back and the fixed safety margin guarantee coincide. More generally, these two guarantee types coincide for all average market rates below the chosen safety margin due to the restriction $g_{t} \geq 0$.
} 


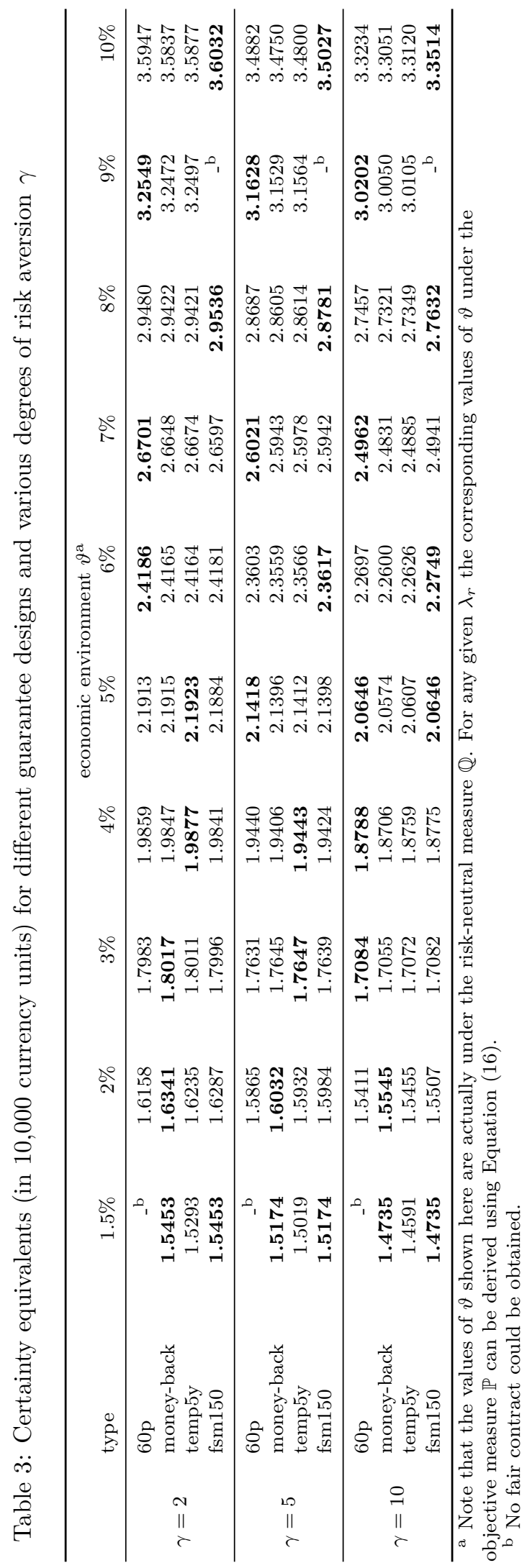


the guarantee are influenced by changes in the average level of interest rates. The analysis is motivated by the current environment of very low interest rates, which is forcing the life insurance industry to reassess its product portfolio, particularly with respect to traditional contracts including long-term interest rate guarantees.

Our main results can be summarized as follows. For new contracts with guarantees based on the 60 percent rule, as proposed by the current regulatory framework, the guarantee value increases significantly in low interest rate environments. Moreover, the alternatives favored by practitioners, the money-back and temporary guarantees, are also subject to this shortcoming as they exhibit the same characteristics, although in a less pronounced fashion. Only under a fixed safety margin guarantee, the guarantee value is almost independent of the interest rate environment. Based on these observations, the spread between average market rate and guaranteed rate is identified to be one of the key drivers of the guarantee value.

Increasing the initial reserves also has a strong impact on the guarantee value as adverse portfolio returns can be compensated by releasing reserves. However, it does not affect the general characteristics across different economic environments. The regulator's influence on the guarantee value through the parameters $y$ (portion of market value earnings to be displayed as book value earnings) and $\delta$ (minimum surplus participation rate) declines notably with increasing market rates. In terms of model risk, the money-back guarantee is most sensitive to a misspecification of asset volatility. However, it is the very same design that leads to the lowest guarantee value in all environments considered. In contrast to this, the fixed safety margin yields stable but high guarantee values, which can become problematic when average market rates drop from a high level. The utility analysis suggests that from the policyholder perspective there seems to be no substantial difference between the different guarantee designs in terms of expected utility. Thus, assuming a utility-maximizing policyholder, the company might choose the guarantee design exhibiting the most desirable guarantee value properties. 
The analysis presented in this paper can be extended in various directions, for example, by improving the model. This could be achieved by reconsidering the short rate model used. It is established that the CIR model produces only a limited range of yield curves. Thus, the term structure model described by Cairns (2004) might be a suitable alternative as it not only produces a wider range of yield curves, but also allows for sustained periods of both high and low interest rates with a "sufficiently high" probability. However, the question as to which model is most suitable in this insurance-related context remains unanswered.

The set of alternative guarantee designs analyzed can also be extended. Inflation-based guarantees might prove beneficial to customers as they guarantee a certain purchasing power in the future instead of some nominal rate. However, pure purchasing power guarantees (where the amount guaranteed at maturity solely depends on the realized inflation rate) do not qualify for favorable tax treatment in Germany as they do not satisfy the mandatory gross premium guarantee. In times of deflation, the guaranteed amount might be nominally lower than the sum of premiums paid even though the purchasing power is higher. If such guarantees are to be introduced in the near future, they most likely will be offered only with unit-linked contracts.

\section{Appendix}

Tables A1 to A6 illustrate the surplus parameters leading to a fair contract and the corresponding decomposition of the fair contract value. 


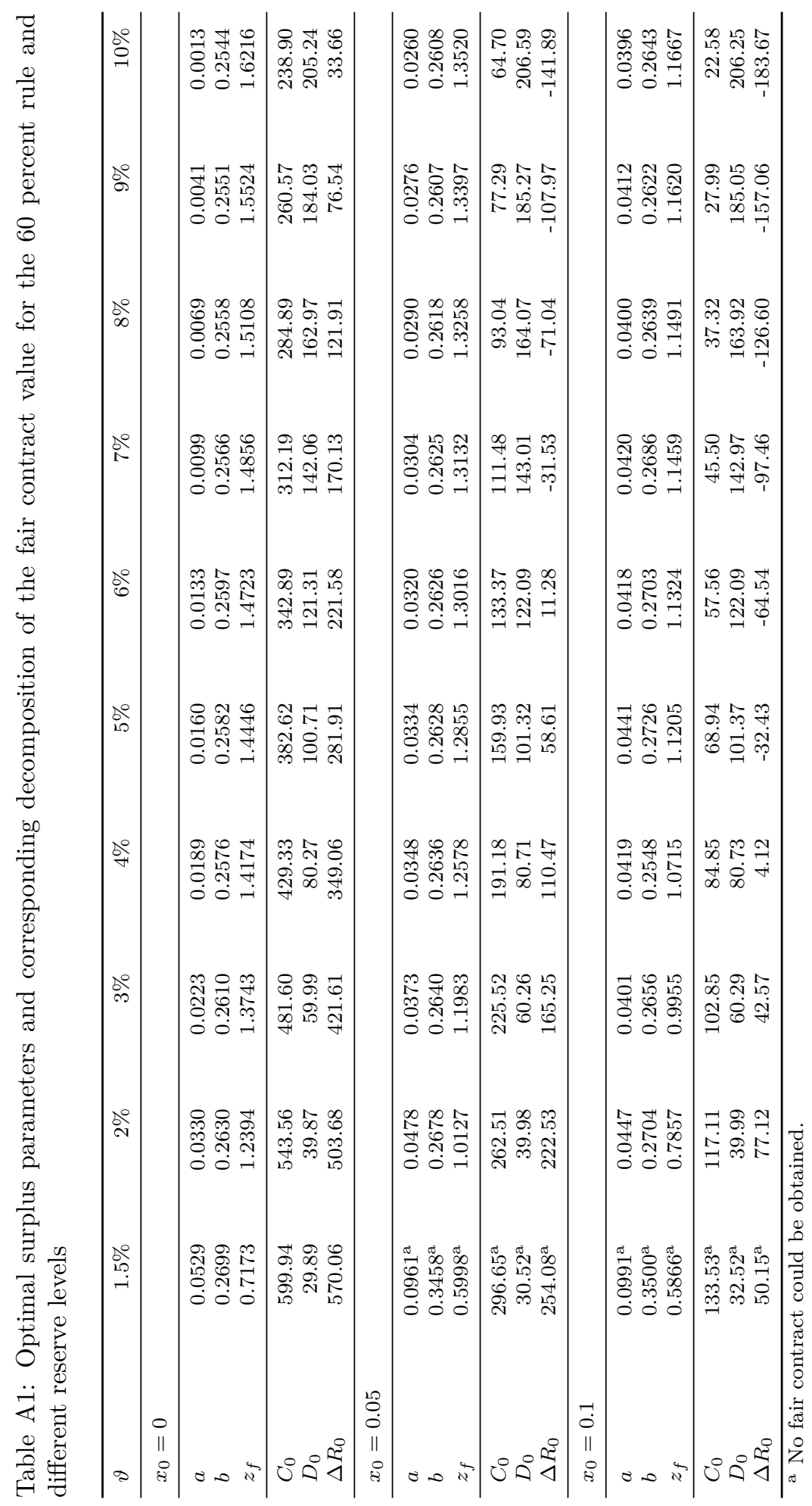




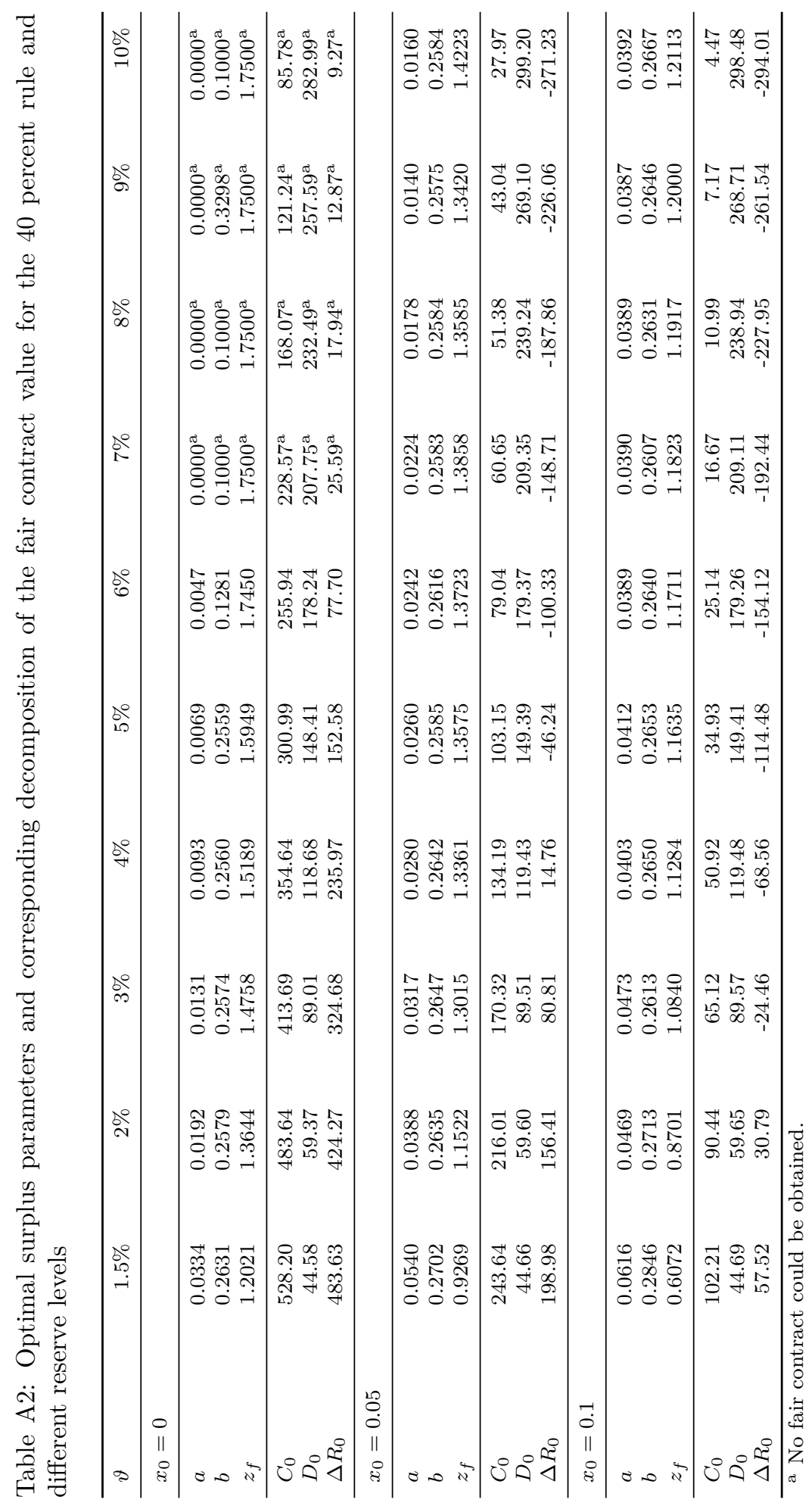




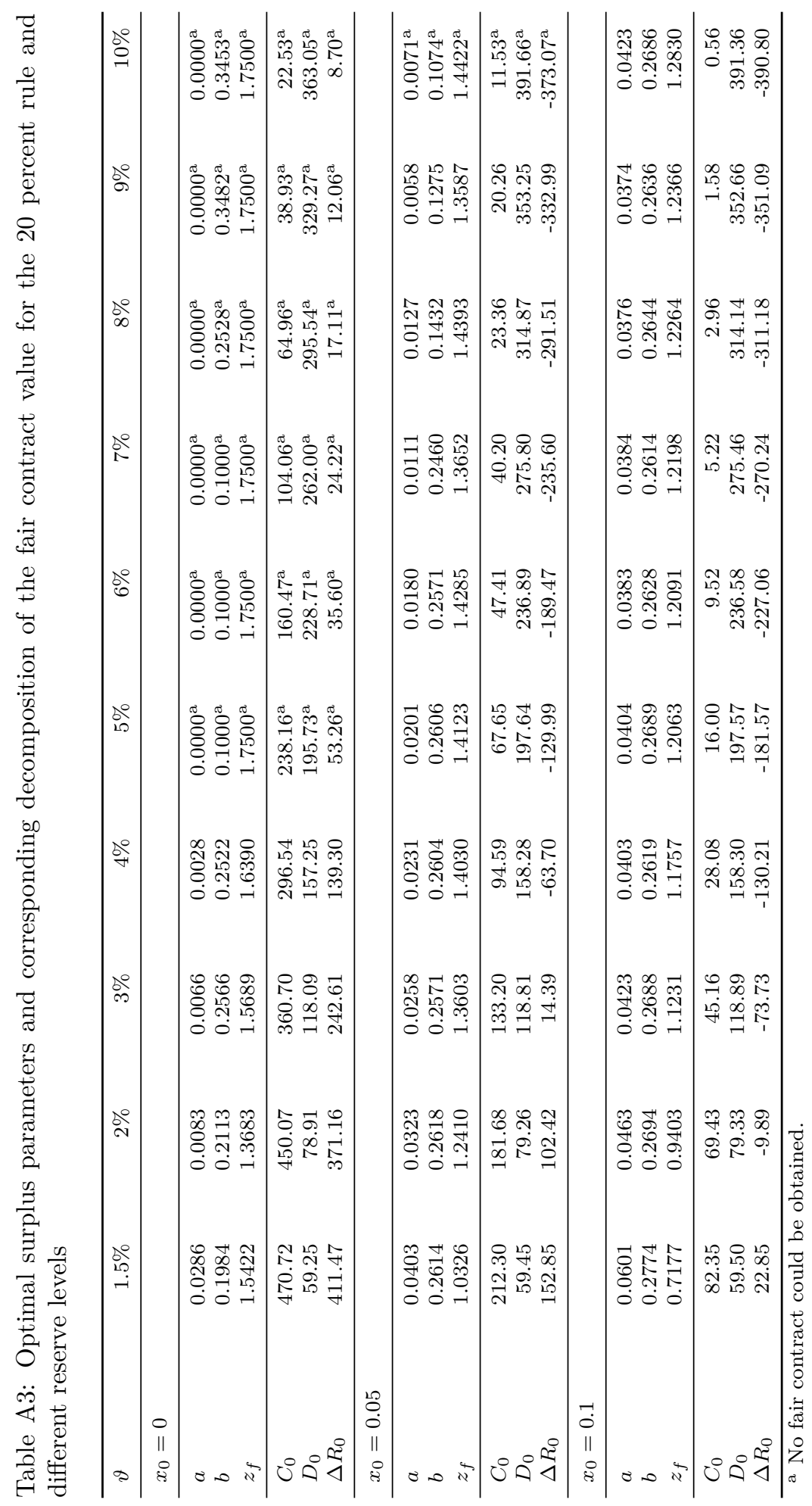




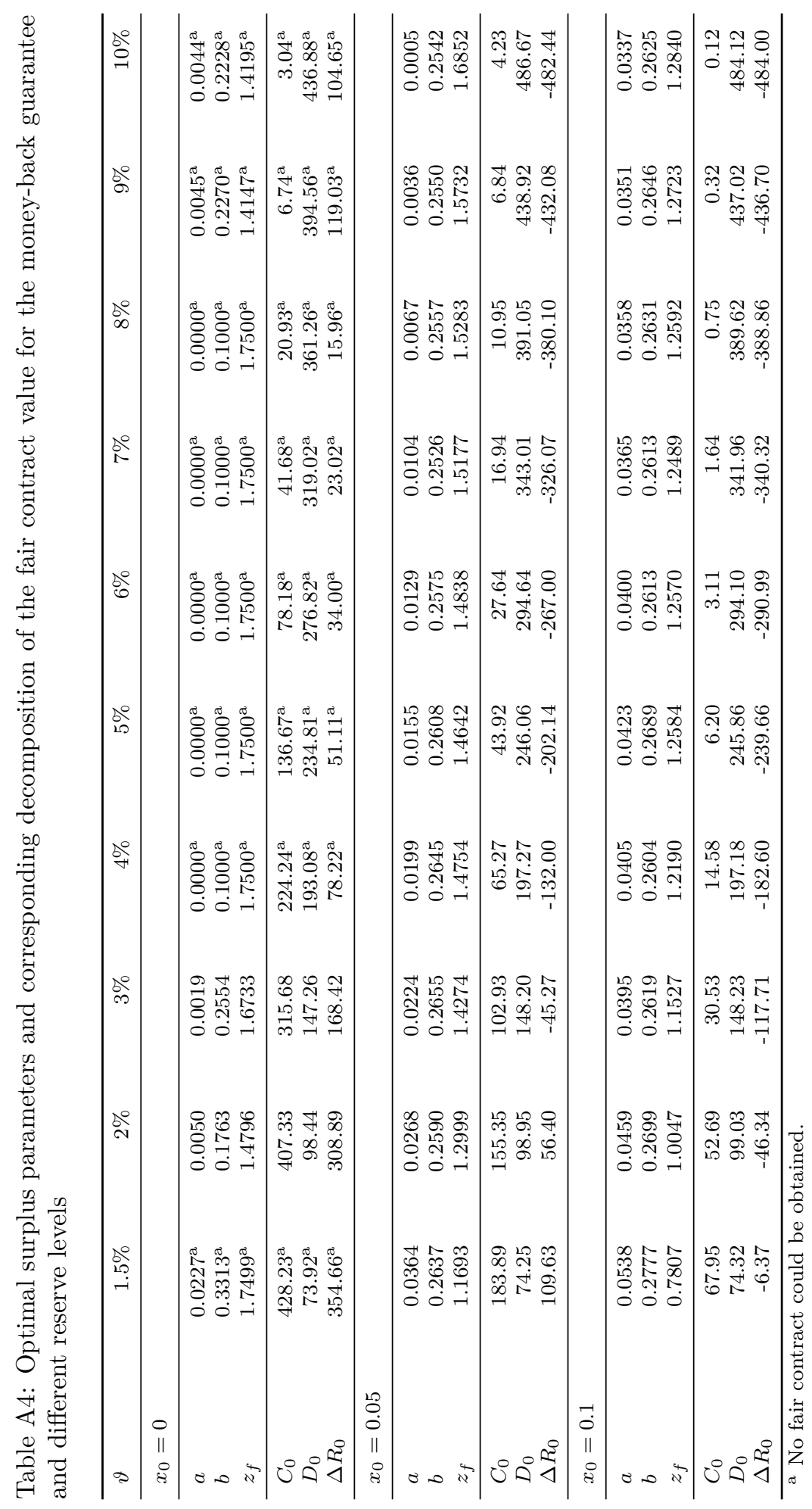




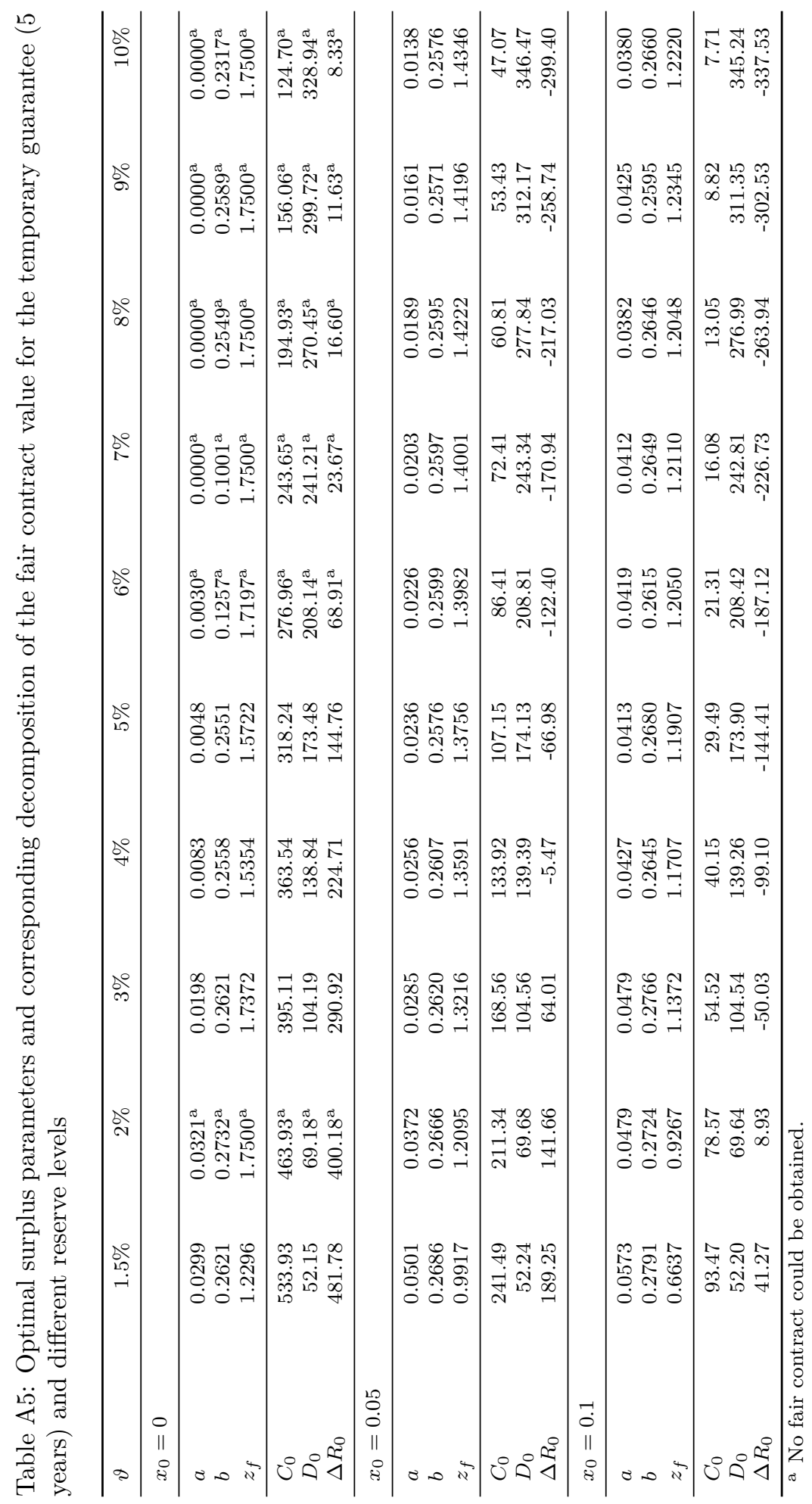




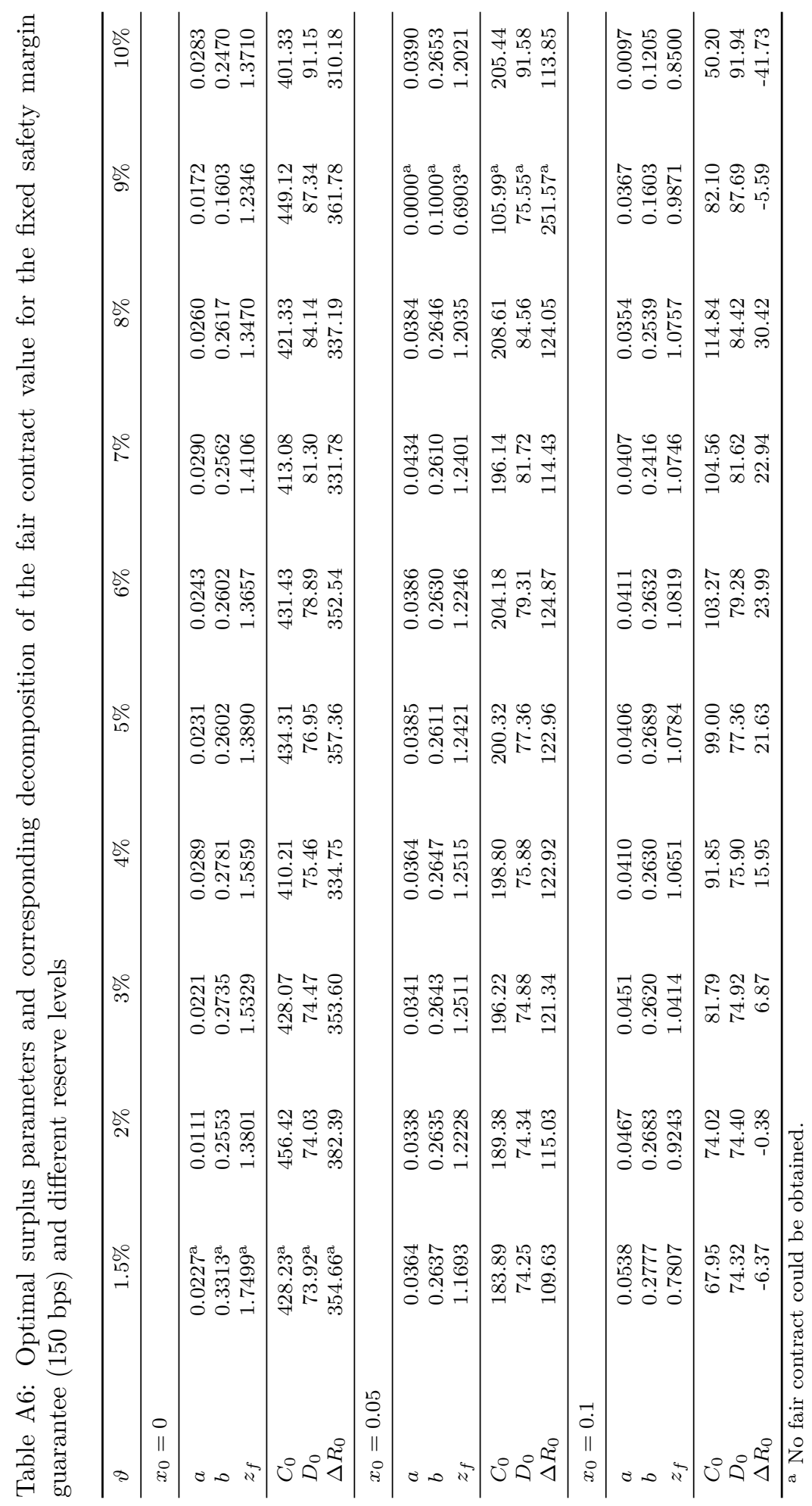




\section{Bibliography}

Bacinello, A.R., 2001. Fair pricing of life insurance participating policies with a minimum interest rate guarantee. ASTIN Bulletin 31, 275-297.

Bacinello, A.R., 2003. Fair valuation of a guaranteed life insurance participating contract embedding a surrender option. Journal of Risk and Insurance 70, 461-487.

Bacinello, A.R., Persson, S.A., 2002. Design and pricing of equity-linked life insurance under stochastic interest rates. Journal of Risk Finance 3, 6-21.

Barbarin, J., Devolder, P., 2005. Risk measure and fair valuation of an investment guarantee in life insurance. Insurance: Mathematics and Economics 37, $297-323$.

Bartels, H.J., Veselčić, M., 2009. Zinsgarantien und Modellrisiko in Lebensversicherungen. Blätter DGVFM 30, 327-361.

Bauer, D., Kiesel, R., Kling, A., Ruß, J., 2006. Risk-neutral valuation of participating life insurance contracts. Insurance: Mathematics and Economics 39, $171-183$.

Brigo, D., Mercurio, F., 2006. Interest Rate Models - Theory and Practice. Springer, Berlin New York. 2nd edition.

Briys, E., de Varenne, F., 1997. On the risk of life insurance liabilities: Debunking some common pitfalls. Journal of Risk and Insurance 64, 673-694.

Broeders, D., Chen, A., Koos, B., 2011. A utility-based comparion of pension funds and life insurance companies under regulatory constraints. Insurance: Mathematics and Economics 49, 1-10.

Büsing, C., 2005. Bewertung der Zinsgarantie in der Lebensversicherung, in: Bäuerle, Mundt (Eds.), Risikomanagement. VVW, Karlsruhe, pp. 2-36.

Cairns, A.J.G., 2004. A family of term structure models for long-term risk management and derivative pricing. Mathematical Finance 14, 415-444.

Cappiello, L., Lo Duca, M., Maddaloni, A., 2008. Country and industry equity risk premia in the euro area: An intertemporal approach. European Central Bank Working Paper Series No. 916. European Central Bank.

Cox, J.C., Ingersoll, J.E., Ross, S.A., 1985. A theory of the term structure of interest rates. Econometrica 53, 385-407.

Cummins, J.D., Miltersen, K.R., Persson, S.A., 2007. International comparison of interest rate guarantees in life insurance contracts. Working Paper. Norwegian School of Economics and Business Administration, Bergen.

Eling, M., Holder, S., 2012. Maximum technical interest rates in life insurance in Europe and the United States: An overview and comparison. Geneva Papers on Risk and Insurance - Issues and Practice, Forthcoming. 
Fromme, H., 2011. Versicherer wollen Hilfe aus Berlin. Financial Times Deutschland September 16, 2011.

Gatzert, N., Kling, A., 2007. Analysis of participating life insurance contracts: A unification approach. Journal of Risk and Insurance 74, 547-570.

Goecke, O., 2011. Das Markenzeichen der Lebensversicherung steht auf dem Spiel. Versicherungswirtschaft 66, 30-33.

Graf, S., Kling, A., Ruß, J., 2011. Risk analysis and valuation of life insurance contracts: Combining actuarial and financial approaches. Insurance: Mathematics and Economics 49, 115-125.

Grosen, A., Jørgensen, P.L., 2000. Fair valuation of life insurance liabilities: The impact of interest rate guarantees, surrender options and bonus policies. Insurance: Mathematics and Economics 26, 37-57.

Grosen, A., Jørgensen, P.L., 2002. Life insurance liabilities at market value: An analysis of insolvency risk, bonus policy, and regulatory intervention rules in a barrier option framework. Journal of Risk and Insurance 69, 63-91.

Hansen, M., Miltersen, K.R., 2002. Minimum rate of return guarantees: The Danish case. Scandinavian Actuarial Journal 4, 280-318.

Heinen, N., 2011. Lebensversicherungen zwischen Baum und Borke. Versicherungswirtschaft $66,318-319$.

Himstedt, G., 2004. Protektor Lebensversicherungs-AG: Erfahrungen im Fall Mannheimer. VVW, Karlsruhe.

Kling, A., Richter, A., Ruß, J., 2007a. The impact of surplus distribution on the risk exposure of with-profit life insurance policies including interest rate guarantees. Journal of Risk and Insurance 74, 571-589.

Kling, A., Richter, A., Ruß, J., 2007b. The interaction of guarantees, surplus distribution, and asset allocation in with-profit life insurance policies. Insurance: Mathematics and Economics 40, 164-178.

van Laarhoven, P.J.M., Aarts, E.H.L., 1987. Simulated Annealing: Theory and Applications. Reidel Kluwer Academic Publishers, Dordrecht.

Mullen, K.M., Ardia, D., Gil, D.L., Windover, D., Cline, J., 2011. DEoptim: An R package for global optimization by differential evolution. Journal of Statistical Software 40, 1-26.

O'Brien, C., 2006. The downfall of Equitable Life in the United Kingdom: The mismatch of strategy and risk management. Risk Management and Insurance Review 9, 189-204.

Pohl, E., 2011. Garantien sind gefährlich. Versicherungswirtschaft 66, 1769.

Price, K., Storn, R., Lampinen, J., 2005. Differential Evolution: A Practical Approach to Global Optimization. Springer, Berlin New York. 
Rymaszewski, P.Z., 2011. Essays on Insurance Economics and the Regulation of Financial Markets. Ph.D. thesis. University of St. Gallen.

Shreve, S.E., 2004. Stochastic Calculus for Finance II: Continuous-Time Models. Springer, New York.

Storn, R., Price, K., 1997. Differential evolution - a simple and efficient heuristic for global optimization over continuous spaces. Journal of Global Optimization $11,341-359$.

Suzuki, T., 2004. Fair Valuation of Japanese insured pension plans: The impact of default risk of insurance companies. Working Paper. Graduate School of Economics, Hokkaido University.

Wagner, J., Schmeiser, H., 2012. The influence of interest rate guarantees and solvency requirements on the asset allocation of life insurance companies. Working Papers on Risk Management and Insurance No. 111. University of St. Gallen.

Zaglauer, K., Bauer, D., 2008. Risk-neutral valuation of participating life insurance in a stochastic interest rate environment. Insurance: Mathematics and Economics 43, 29-40.

Zemp, A., 2011. Risk comparison of different bonus distribution approaches in participating life insurance. Insurance: Mathematics and Economics 49, 249-264. 